\title{
Systemic arterial hypertension and cognition in adults: effects on executive functioning
}

Hipertensão arterial sistêmica e cognição em adultos: efeitos no funcionamento executivo

Natália Cristina MORAES'. Henrique Cotchi Simbo MUELA², Claudia Maia MEMÓRIA', Valéria Aparecida da COSTA-HONG ${ }^{3}$, Michel Ferreira MACHADO ${ }^{3}$, Mario Amore CECHINHI', Ricardo NITRINI', Luiz Aparecido BORTOLOTTO³, Monica Sanches YASSUDA'

\begin{abstract}
Background: Central nervous system changes associated to systemic arterial hypertension (SAH) are progressive and may cause negative effects on cognitive performance. The objective of this study was to investigate the relation between SAH and the components of executive functions (EF), inhibitory control (IC), updating and shifting, comparing a control group (without SAH) to patients with SAH, in two levels of severity. Methods: The protocol included the following tests to evaluate EF components: T.O.V.A. Test (IC), Backward Digit Span from Wechsler Adults Intelligence Scale (WAIS-III), Phonemic and Semantic Verbal Fluency (updating), and Trail Making Test Part B (shifting). Results: A total of 204 participants was included: 56 from the Control Group (CG), 87 SAH stage 1, and 61 SAH stage 2. The groups were not

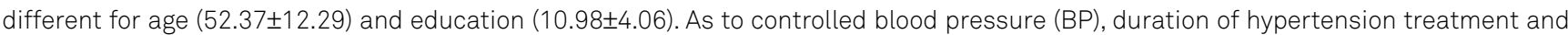
number of drugs, the SAH 2 group had a worse BP control, longer duration of hypertension treatment and use of more drugs when compared to the SAH 1. The findings revealed that patients with more severe hypertension presented worse performance in updating (Backward Digit Span, phonemic and semantics VF) and shifting (Trail Making Test Part B). Conclusion: The results suggest that patients with SAH have a significant impairment in EF, more specifically in updating and shifting. Besides that, such damage may be directly proportional to the severity of $\mathrm{SAH}$. It is suggested that future studies include neuroimaging exams to exclude possible cerebrovascular diseases.
\end{abstract}

Keywords: Hypertension; Cognition; Executive Function.

RESUMO

Introdução: As alterações do sistema nervoso central associadas à hipertensão arterial sistêmica (HAS) são progressivas e podem ocasionar efeitos negativos no desempenho cognitivo. 0 objetivo deste estudo foi investigar a relação entre a HAS e os componentes das funções executivas (FE), controle inibitório (CI), atualização e alternância, comparando um grupo controle (sem HAS) a pacientes com HAS, em dois níveis de gravidade. Métodos: 0 protocolo incluiu os seguintes testes para avaliar os componentes das FE: T.O.V.A. Test (CI), Dígitos Ordem Indireta da Escala de Inteligência Wechsler para Adultos (Wechsler Adults Intelligence Scale - WAIS-III), Fluência Verbal fonêmica e semântica (atualização) e Teste de Trilhas parte B (alternância). Resultados: Foram incluídos 204 participantes, sendo 56 do Grupo Controle (GC), 87 HAS estágio 1 (HAS 1) e 61 de HAS estágio 2 (HAS 2). Os grupos não foram diferentes em relação à idade (52,37士12,29) e escolaridade $(10,98 \pm 4,06)$. Em relação à pressão arterial (PA) controlada, tempo de tratamento da HAS e número de medicações, o grupo HAS 2 apresentou pior controle de PA, mais tempo de tratamento da HAS e uso de maior número de medicações quando comparado ao grupo HAS 1. Os achados revelaram que os pacientes com HAS em estágio mais grave apresentaram pior desempenho nos testes de alternância (Teste de Trilhas parte B) e atualização (Dígitos Ordem Indireta, FV fonêmica e semântica). Conclusão: Esses resultados sugerem que pacientes com a HAS possuem prejuízo significativo em FE, especificamente em alternância e atualização, e que esse prejuízo pode ser diretamente proporcional à gravidade da HAS. Sugere-se que, em estudos futuros, incluam-se exames de neuroimagem com o objetivo de excluir possiveis doenças cerebrovasculares.

Palavras-chave: Hipertensão; Cognição; Função Executiva.

\footnotetext{
${ }^{1}$ Universidade de São Paulo, Department of Neurology, São Paulo SP, Brazil.
}

${ }^{2}$ Universidade Agostinho Neto, Faculty of Medicine, Department of Physiology, Luanda, Angola.

${ }^{3}$ Universidade de São Paulo, Hypertension Unit, Heart Institute, São Paulo SP, Brazil.

Natália Cristina MORAES (D) https://orcid.org/0000-0002-8439-6828; Henrique Cotchi Simbo MUELA (iD https://orcid.org/0000-0002-0071-9555; Claudia Maia MEMÓRIA iD https://orcid.org/0000-0003-3951-3543; Valéria Aparecida da COSTA-HONG (iD) https://orcid.org/0000-0003-1639-8095; Michel Ferreira MACHADO (iD https://orcid.org/0000-0003-2326-5231; Mario Amore CECHINHI (iD) https://orcid.org/0000-0001-5853-3422;

Ricardo NITRINI (D) https://orcid.org/0000-0002-5721-1525; Luiz Aparecido BORTOLOTTO ID https://orcid.org/0000-0002-4865-6442;

Monica Sanches YASSUDA (iD) https://orcid.org/0000-0002-9182-2450

Correspondence: Natália Cristina Moraes; E-mail:moraes.na@gmail.com

Conflict of interest: There is no conflict of interest to declare.

Received on October 24, 2019; Received in its final form on January 27, 2020; Accepted on March 30, 2020. 


\section{INTRODUCTION}

Systemic arterial hypertension (SAH) is a chronic disease, with multifactorial causes associated to functional, structural and metabolic changes ${ }^{1}$. More recently, researchers have examined the impact of SAH on cognition. There is a consensus regarding a significant relation between cerebral and cardiovascular health ${ }^{2}$, such as how the chronic increase in blood pressure (BP) contributes to negative outcomes in brain functions ${ }^{3,4}$.

There is evidence to suggest that white matter lesions are more prevalent among persons with $\mathrm{SAH}$, and that chronically elevated BP may be associated to lesion severity. ${ }^{5}$ SAH is also associated to changes in the small arteries and arterioles that supply blood to the subcortical white matter and the basal ganglia and may result in small vessel disease ${ }^{6}$. Although the course of cerebrovascular disease may be asymptomatic, silent infarcts in the white matter may affect the connections between the prefrontal cortex and the deep subcortical nuclei, and may interrupt the connectivity between these regions, resulting in altered functioning in the frontal lobes? In general, individuals with frontal lobe damage demonstrate impairment related to executive functions $(\mathrm{EF})^{8}$.

The concept of EF involves several abilities that include various components of cognitive processing. It is of utmost importance to everyday life, because of its essential role in regulating thoughts and behaviors in an ever-changing environment, which demands constant flexibility 9 . When thinking about health, EF can play an important role in the development of positive behaviors, such as physical activity, which requires organization and planning, and the avoidance of negative behaviors, such as smoking, considering that inhibitory control is essential. It is possible that the associations between SAH and EF are reciprocal, that is, small vessel disease may impact EF deficits over time, and EF, in turn, may influence disease progression by its negative impact on medication adherence and other health behaviors ${ }^{10}$.

Some theoretical models consider inhibition (inhibitory control), updating (working memory) and shifting or cognitive flexibility as the main domains of $\mathrm{EF}^{11,12}$. Inhibitory control (IC) refers to the ability to inhibit responses or behaviors if a reaction is inappropriate in a given context. Updating is responsible for clearing and updating working memory for efficient use of processing capacity when information is no longer relevant to current objectives. Shifting is the ability to alternate between different tasks, or stimuli, requiring rules to be maintained or disengaged as needed ${ }^{11,12,13,14}$.

Few studies have investigated the effect of SAH on the different components of EF, which may be affected differently by this condition. Thus, the present study investigated which domains of EF are more significantly affected by the presence of SAH, at two levels of severity, in a sample not affected by dementia. In addition, it aimed to test if changes in attention and processing speed might explain possible deficits observed in EF among participants with SAH in the control group.

\section{METHODS}

\section{Participants}

The sample consisted of hypertensive patients followed up at Instituto do Coração (INCOR), São Paulo City, at two levels of disease severity: stage 1 , moderate $(n=87)$; and stage 2 , severe ( $\mathrm{n}=61$ ), and by a control group (normotensive, $\mathrm{CG}, \mathrm{n}=56$ ).

Patients from the Hypertension Unit of INCOR were consecutively recruited from June 2013 to December 2015. The CG participants were recruited among patients without cardiovascular disease followed up yearly at INCOR, as part of a protocol for cardiovascular assessment in healthy participants ${ }^{15}$.

Patients with the following conditions were excluded: age $<21$; cerebrovascular disease (previous stroke or transient ischemic attack); diabetes mellitus; current smoker; arrhythmias; heart failure with left ventricular dysfunction; known neurodegenerative or psychiatric disease; and illiteracy. The study was submitted to the local ethics committee and later approved. It received the protocol number 1.328.094 and all participants provided their written informed consent.

\section{Procedures}

\section{Blood pressure measurement}

Patients with SAH were divided into 2 levels of SAH severity, according to their BP levels or medication use (SAH 1: BP, 140-159/90-99 or use of 1 or 2 antihypertensive drugs; SAH 2: BP, $\geq 160 / 100$ or use of $\geq 3$ drugs). Three groups were comparatively analyzed: normotensive, SAH 1, and SAH 2. The automatic device Omron, model HEM-750 CP, was used in the right upper limb, with the participant sitting after five minutes of rest. The measurement was performed three times with 1-minute intervals between them to calculate the mean of the three measurements.

\section{Assessment of executive function}

All participants completed a neuropsychological battery examination. The Mini-mental State Examination (MMSE) and Montreal Cognitive Assessment (MoCA) were used to assess global cognition. The MMSE cutoff scores were used to identify abnormal cognition in this study: $\leq 22$ for patients with one to five years of education; $\leq 23$ for those with six-11 years of education; and $\leq 24$ for those with $\geq 12$ years of education ${ }^{16}$. The MoCA score of $\geq 26$ was considered normal ${ }^{17}$.

The neuropsychological tests were chosen according to the guidelines offered by the National Institute of Neurological Disorders and Stroke-Canadian Stroke Network standards ${ }^{18}$ and by the recommendations of the Brazilian Academy of Neurology ${ }^{19}$.

In order to assess the EF components, following the models of Miyake et al. ${ }^{11}$ and Diamond ${ }^{13}$, the following tests were used: T.O.V.A. Test (Test of Variable Attention Test) for IC, Backward Digit Span and Verbal Fluency (VF) Phonemic and Semantic for Updating, and Trail Making Test Part B (TMT-B) 
for Shifting. The T.O.V.A. Test requires the participant to press a microswitch when a target stimulus appears at the top of the computer screen and not press it when the stimulus appears at the bottom. In the Backward Digit Span, the participant is asked to repeat a sequence of numbers from the last to the first. For VF tasks, the participant is requested to say words from a given semantic category or begging with a certain letter. Finally, in the TMT-B, the participant alternates between numbers and letters, with numbers in a crescent order and letters in alphabetical order, demanding that the rule be maintained and disengaged. Participants also completed the Trail Making Test Part A (TMT-A) and Forward Digit Span to evaluate attention. As for measuring speed of cognitive processing, participants completed the Digit Symbol test.

For assessing other aspects of cognition, the protocol included the Boston Naming Test, Rey Auditory-Verbal Learning Test (RAVLT), Rey-Osterrieth complex figure test (ROCF) and Clock Drawing Test.

Participants also answered the Self-Reporting Questionnaire (SRQ-20), which investigates non-psychotic symptoms associated to common mental disorders, such as insomnia, fatigue, irritability, forgetfulness, difficulty in concentrating, and somatic complaints ${ }^{20}$.

\section{Statistical analysis}

The Kolmogorov-Smirnov test was used to verify if the scores of the variables followed a normal distribution. Descriptive statistics were performed comparing the three clinical groups (CG versus SAH 1 versus SAH 2) using ANOVA for data following normal distribution, and Mann-Whitney or Kruskal-Wallis test for data not following normal distribution. When there was a significant difference between groups, multiple comparisons were carried out with the Bonferroni test. Effect sizes (Hedge g value) were calculated for the differences between the means, standardized by the standard deviation of all neuropsychological test scores, between the CG versus SAH 1, and the CG versus the SAH 2. The Hedge g values of $0.2,0.5$ and 0.8 can be considered small, medium and large effects, respectively ${ }^{21}$. Additionally, ANCOVA were performed with IC, updating and shifting, controlling for the effects of attention measures (TMT-A) and speed of cognitive processing (WAIS-III Digit Symbol).

\section{RESULTS}

\section{Sample characteristics}

The characteristics of the sample are presented in Table 1. The groups were not significantly different in terms of age, gender and schooling. The mean age was $52.37 \pm 12.29$, ranging from 21 to 80 years old, mean schooling was $10.98 \pm 4.06$, ranging from 4 to 22 years. The sample consisted of $71.2 \%$ of women. The SAH 1 group differed as to race compared to the CG. There was a greater presence of Caucasian people in the SAH 1 group. The SAH 2 group presented higher weight and, consequently, higher BMI when compared to the CG. The SAH 2 group had more SAH time (time of diagnosis), number of medications, worse BP control, compared to the SAH 1. SAH 1 and 2 scored higher on the SRQ-20 than the CG, indicating greater presence of symptoms compatible with common mental illness.

\section{Cognitive performance}

For global cognition there was a significant difference between the groups for the MMSE and the MoCA (Table 2). For the MMSE, the SAH 2 had a lower score than the CG. For the MoCA, the SAH 2 group had lower scores than the $\mathrm{CG}$ and the SAH 1 group, and the latter two did not differ. For episodic memory tests, there was a significant difference between the clinical groups in the RAVLT, in the sum of the recall scores (A1-A5). The SAH 2 group performed worse than the CG and SAH 1, which did not differ. The SAH 2 group also

Table 1. Sociodemographic and clinical characteristics of the sample.

\begin{tabular}{|c|c|c|c|c|}
\hline Variables & $\begin{array}{c}C G \\
(n=56)\end{array}$ & $\begin{array}{l}\text { SAH } 1 \\
(n=87)\end{array}$ & $\begin{array}{l}\mathrm{SAH} 2 \\
(\mathrm{n}=61)\end{array}$ & $p$-value \\
\hline Age, mean $\pm S D, y$ & $53.75 \pm 13.5$ & $52.44 \pm 12.7$ & $51.02 \pm 10.5$ & 0.354 \\
\hline Gender, women, n (\%) & $32(58.2)$ & $49(55.7)$ & $36(59.0)$ & $0.912(*)$ \\
\hline Education, mean $\pm S D, y r$ & $11.73 \pm 3.65$ & $11.16 \pm 4.0$ & $10.03 \pm 4.35$ & 0.052 \\
\hline Skin color, Caucasian, n (\%) & $34(61.8)^{b}$ & $68(77.3)^{a}$ & $36(59.0)$ & $<0.001(*)$ \\
\hline Height, mean $\pm S D(k g)$ & $72.13 \pm 14.55^{\circ}$ & $77.65 \pm 14.69$ & $83.19 \pm 13.49^{a}$ & $<0.001$ \\
\hline BMI, mean $\pm S D\left(k g / m^{2}\right)$ & $26.54 \pm 3.95^{c}$ & $28.63 \pm 49.8$ & $30.30 \pm 4.60^{a}$ & $<0.001$ \\
\hline BP controlled, n (\%) & - & $50(57.5)^{c}$ & $22(36.1)^{b}$ & $0.010 *$ \\
\hline SAH Time, mean $\pm S D, y$ & - & $7.66 \pm 6.84^{\circ}$ & $13.31 \pm 9.05^{b}$ & $<0.001 * *$ \\
\hline Number of drugs & - & $1.43 \pm 0.74^{\circ}$ & $3.92 \pm 1.17^{b}$ & $<0.001 *$ \\
\hline SRQ 20 & $4.75 \pm 3.77^{\mathrm{b}, \mathrm{c}}$ & $6.65 \pm 4.31^{\mathrm{a}}$ & $8.07 \pm 4.65^{a}$ & $<0.001$ \\
\hline
\end{tabular}

Total Sample n=204; CG: Control Group; SAH 1: Systemic Arterial Hypertension Stage 1; SAH 2: Systemic Arterial Hypertension Stage 2; BMI: Body Mass Index; BP controlled: Blood Pressure Controlled; SAH Time: Time of treatment of Systemic Arterial Hypertension; $p$-value refers to the Kruskal-Wallis test, Chi-square test $(*)$ and Mann-Whitney test (**); Bonferroni multiple comparisons: a - differs significantly from CG $(p<0.05)$; b - differs significantly from the SAH 1 group $(p<0.05)$; $c$ - differs significantly from SAH 2 group $(p<0.05)$. 
performed worse in the delayed recall of the ROCF, when compared to the CG. In the attention tasks, the SAH 2 group was slower in the TMT-A, when compared to the CG. The same occurred in the Digit Symbol test, in which the CG obtained higher performance than the SAH 2 group.

\section{Executive functions performance}

For IC, there was no statistical difference between groups (Table 3). For updating, there were significant differences between the clinical groups in Backward Digit Span, and VF (semantic and phonemic). For the Backward Digit Span test,

Table 2. Cognitive performance according to the presence and severity of SAH.

\begin{tabular}{|c|c|c|c|c|c|c|c|c|}
\hline \multirow{2}{*}{ Variable } & \multirow{2}{*}{$\begin{array}{c}\mathrm{CG} \\
(n=56)\end{array}$} & \multirow{2}{*}{$\begin{array}{l}\text { SAH } 1 \\
(n=87)\end{array}$} & \multirow{2}{*}{$\begin{array}{l}\mathrm{SAH} 2 \\
(n=61)\end{array}$} & \multirow{2}{*}{$\mathrm{p}$-value } & \multicolumn{2}{|c|}{ CG X SAH 1} & \multicolumn{2}{|c|}{$\mathrm{CG} \times \mathrm{SAH} 2$} \\
\hline & & & & & gHedges & $95 \% \mathrm{Cl}$ & gHedges & $95 \% \mathrm{Cl}$ \\
\hline \multicolumn{9}{|l|}{ Global Cognition } \\
\hline MMSE & $27.73 \pm 2.04^{\circ}$ & $27.41 \pm 2.07$ & $26.77 \pm 2.03^{a}$ & 0.021 & -0.155 & $-0.92-0.181$ & -0.472 & $-0.84-0.104$ \\
\hline MoCA & $25.05 \pm 3.31^{c}$ & $24.94 \pm 2.83^{c}$ & $23.50 \pm 3.45^{a, b}$ & $0.01 *$ & -0.036 & $-0.372-0.299$ & -0.458 & $-0.826-0.091$ \\
\hline \multicolumn{9}{|l|}{ Episodic Memory } \\
\hline $\begin{array}{l}\text { RAVLT } \\
\text { A1-A5 }\end{array}$ & $42.05 \pm 7.76^{c}$ & $42.55 \pm 9.62^{\circ}$ & $38.27 \pm 9.13^{a, b}$ & $0.014^{\star}$ & 0.056 & $-0.28-0.392$ & -0.445 & $-0.812-0.077$ \\
\hline RAVLT late & $8.66 \pm 3.1$ & $8.42 \pm 3.66$ & $7.38 \pm 3.63$ & 0.098 & -0.07 & $-0.405-0.266$ & -0.378 & $-0.744-0.012$ \\
\hline REY late & $13.64 \pm 7.84$ & $13.96 \pm 8.16$ & $11 \pm 7.15$ & $0.066^{*}$ & 0.04 & $-0.296-0.376$ & -0.353 & $-0.718-0.013$ \\
\hline \multicolumn{9}{|l|}{ Language } \\
\hline BNT & $54.82 \pm 4.68$ & $53.37 \pm 5.87$ & $52.91 \pm 5.66$ & 0.081 & -0.267 & $-0.604-0.071$ & -0.366 & $-0.732-0.001$ \\
\hline \multicolumn{9}{|l|}{ Attention } \\
\hline Digit Span Forward & $7.42 \pm 1.89$ & $7.77 \pm 2.33$ & $6.92 \pm 1.58$ & 0.18 & 0.161 & $-0.175-0.498$ & -0.288 & $-0.653-0.076$ \\
\hline TMT-A (seconds) & $56.52 \pm 37.59^{c}$ & $66.40 \pm 51.39$ & $72.92 \pm 35.16^{a}$ & $<0.001$ & 0.212 & $-0.124-0.549$ & 0.451 & $-0.084-0.819$ \\
\hline \multicolumn{9}{|l|}{ Processing Speed } \\
\hline Digit Symbol & $51.96 \pm 19.06^{c}$ & $47.37 \pm 18.2$ & $41.85 \pm 16.79^{a}$ & 0.014 & -0.248 & $-0.585-0.089$ & -0.564 & $-0.934-0.195$ \\
\hline \multicolumn{9}{|l|}{ Praxia } \\
\hline REY copy & $32.31 \pm 7.17^{c}$ & $31.15 \pm 6.75$ & $30.16 \pm 7.78^{a}$ & 0.037 & -0.168 & $-0.504-0.169$ & -0.287 & $-0.651-0.078$ \\
\hline CDT & $4.38 \pm 1.10$ & $4.14 \pm 1.48$ & $4.10 \pm 1.32$ & 0.441 & -0.178 & $-0.515-0.158$ & -0.23 & $-0.593-0.134$ \\
\hline
\end{tabular}

Total Sample n=204; CG: Control Group; SAH 1: Systemic Arterial Hypertension Stage 1;SAH 2: Systemic Arterial Hypertension Stage 2; 95\%Cl: 95\% confidence interval; error of commission MMSE: Mini Mental State Examination; MoCA: Montreal Cognitive Assessment; RAVLTA1-A5: sum of the five evocations of the Rey Auditory-Verbal Learning Test: RAVLT late: Late evocation of Rey Auditory-Verbal Learning Test: REY late: evocation after 30 minutes of the Rey Complex Figure; BNT: Boston Naming Test; Digit Span Forward: Subtest Digit Span Forward from Wechsler Adult Intelligence III; TMT-A: time of execution of the Trail Making Test part A; Symbol Digits: Subtests Symbol Digit from of Wechsler Adult Intelligence III; CDT: Clock Drawing Test corrected by Shulman score; $p$-value refers to the Kruskal-Wallis test; *ANOVA test; Bonferroni multiple comparisons: a — differs significantly from $\mathrm{CG}(\mathrm{p}<0.05) ; \mathrm{b}$ - differs significantly from the SAH 1 group $(p<0.05) ; c$ - differs significantly from SAH 2 group $(p<0.05)$.

Table 3. Performance in the tests that evaluate the EF components according to the presence and severity of SAH.

\begin{tabular}{|c|c|c|c|c|c|c|c|c|}
\hline \multirow{2}{*}{ Variables } & \multirow{2}{*}{$\begin{array}{c}\mathrm{CG} \\
(n=56)\end{array}$} & \multirow{2}{*}{$\begin{array}{l}\text { SAH } 1 \\
(n=87)\end{array}$} & \multirow{2}{*}{$\begin{array}{l}\text { SAH } 2 \\
(n=61)\end{array}$} & \multirow{2}{*}{$p$-value } & \multicolumn{2}{|c|}{$\mathrm{CG} \times \mathrm{SAH} 1$} & \multicolumn{2}{|c|}{$\mathrm{CG} \times \mathrm{SAH} 2$} \\
\hline & & & & & gHedges & $95 \% \mathrm{Cl}$ & gHedges & $95 \% \mathrm{Cl}$ \\
\hline \multicolumn{9}{|l|}{ Inhibitory Control } \\
\hline $\begin{array}{l}\text { Errors of } \\
\text { commission T.O.V.A. }\end{array}$ & $9.20 \pm 8.53$ & $11.3 \pm 9.39$ & $11.38 \pm 11.59$ & 0.223 & 0.232 & $-0.105-0.569$ & 0.213 & $-0.151-0.577$ \\
\hline \multicolumn{9}{|l|}{ Updating } \\
\hline Digit Span Backward & $4.84 \pm 1.60^{\circ}$ & $4.63 \pm 1.99$ & $3.78 \pm 1.59^{a}$ & 0.004 & -0.114 & $-0.45-0.222$ & -0.665 & $-1.037-0.292$ \\
\hline VF semantic & $17.27 \pm 4.93^{\circ}$ & $17.25 \pm 5.00^{\circ}$ & $13.95 \pm 3.55^{a, b}$ & $<0.001^{*}$ & -0.004 & $-0.34-0.332$ & -0.778 & $-1.154-0402$ \\
\hline VF phonemic & $36.50 \pm 10.82^{c}$ & $34.54 \pm 10.53^{c}$ & $29.93 \pm 11.07^{a, b}$ & 0.003 & -0.184 & $-0.521-0.152$ & -0.6 & $-0.971-0.229$ \\
\hline \multicolumn{9}{|l|}{ Shifting } \\
\hline TMT-B (seconds) & $131.9 \pm 94.02^{\circ}$ & $144.03 \pm 76.59$ & $172.10 \pm 109.92^{a}$ & 0.015 & 0.145 & $-0.191-0.481$ & 0.392 & $-0.026-0.758$ \\
\hline TMT-B minus TMT-A & $82.55 \pm 85.92$ & $89.37 \pm 63.33$ & $106.13 \pm 94.61$ & 0.135 & 0.093 & $-0.243-0.429$ & 0.26 & $-0.104-0.625$ \\
\hline
\end{tabular}

Total Sample $n=204$; CG: Control Group; SAH 1: Systemic Arterial Hypertension Stage 1; SAH 2: Systemic Arterial Hypertension Stage 2; 95\%Cl: 95\% confidence interval; errors of commission T.O.V.A.: Errors of commission of the Test of Variables of Attention; Digit Span: Subtest Backward of Wechsler Adult Intelligence III; VF semantic: Verbal Fluency Semantic; VF phonemic: Verbal Fluency Phonemic; TMT-B: Trail Making Test part B; TMT-B minus TMT-A: time in seconds of part B execution minus the time in seconds of part A of the Trail Making Test; $p$-value refers to the Kruskal-Wallis test; ${ }^{\star}$ ANOVA test; Bonferroni multiple comparisons: a - differs significantly from CG $(p<0.05)$; b - differs significantly from the SAH 1 group ( $<<0.05)$; $c$ - differs significantly from SAH 2 group ( $p<0.05)$. 
the CG and SAH 2 were statistically different, with the CG obtaining a higher score. In VF tests, the SAH 2 group had worse scores than the CG and SAH 1, which did not differ from each other. As to shifting, there was a significant difference between the SAH 2 and the CG groups, with worse scores for the SAH 2 group in the TMT-B.

To accomplish the second objective of the study, the analyses described in Table 2 were repeated, controlling for measures of attention (TMT-A, Forward Digit Span) and cognitive processing speed (Digit Symbol). The results were statistically equivalent to those observed in Table 2 . These results suggested that the group differences observed in Table 2 were not explained by the variability of attention and processing speed tests.

\section{DISCUSSION}

This study aimed to investigate the relation between $\mathrm{SAH}$ and EF, comparing normotensive patients with hypertensive ones at two levels of severity. The results indicated that participants in the more severe hypertension stage had worse performance in EF tasks. When EF tasks were divided into three components (IC, updating and shifting), results indicated that updating and shifting were affected in the most severe SAH stage. There was no statistical difference between groups in relation to IC. Additionally, variability in measures of attention and speed of cognitive processing did not explain group variability in updating and shifting. In addition, it should be noted that there was no difference in cognitive scores between the CG and the SAH 1 groups. This may suggest that cognitive deficits associated to $\mathrm{SAH}$ is observable in more severe stages of the disease. This finding highlights the need to classify individuals with SAH in levels of severity in studies about the effects of the disease in target organs.

\section{Global cognition}

SAH 2 participants presented worse scores in the tests of global cognition (MMSE and MoCA) when compared to the other groups. This finding is in line with a previous study $^{22}$, in which the association between SAH and worse global cognition was evidenced as well. Similar findings were reported by Hannesdottir et al. ${ }^{23}$, when the MoCA test seemed more sensitive in identifying cognitive deficits associated to HAS. Webb et al. ${ }^{17}$ compared impairment in the MMSE versus the MoCA in a sample of participants with $\mathrm{SAH}$. The MoCA was significantly more sensitive to identify cognitive impairment associated to SAH. These findings are divergent from Fitri and Rambe ${ }^{24}$, as in this study there was no significant difference in the total MoCA score between hypertensive and normotensive individuals. However, there was a statistical significance in the subtests of EF and visuospatial function.

\section{Executive functions performance}

\section{Inhibitory control}

According to the literature review by Moraes on SAH and $\mathrm{EF}^{25}$, IC is altered in people with $\mathrm{SAH}$, and the most frequently used task to evaluate this ability is the Stroop Test. In the studies by Li et al. ${ }^{26}$, Bucur and Madden ${ }^{27}$, the participants with SAH performed worse in the Stroop Test when compared to the normotensive ones. However, in the present study, this effect was not observed. An explanation for this incongruence refers to the choice of IC test, because the Stroop Test and the T.O.V.A may assess IC differently. The T.O.V.A. Test is a simple, continuous performance computerized task that evaluates IC measures and attention with errors of commission, i.e, which may relate to impulsivity ${ }^{28}$. In this task, IC is evaluated by the individual's ability not to click on a switch when the target stimulus appears at the bottom of the screen. In the Stroop test, the task is more complex, as in plate 3 there is the need to inhibit an almost automatic activity (reading of the written word), in favor of naming the color of the ink, in which the word is printed.

Thus, data from the present study seem to suggest that very simple IC tasks are not able to identify possible changes in this ability in association with SAH. New studies should include more complex measures of IC, such as the Stroop test, go-no-go tasks or similar measures.

\section{Updating}

The measures chosen to measure updating in the present sample were the Backward Digit Span, semantic and phonemic VF. The results showed significantly lower scores in the SAH 2 group than the CG in these tests, in disagreement with studies in literature.

The study by Hannesdottir et al. ${ }^{23}$ aimed to investigate which cognitive abilities were most affected by SAH in participants treated pharmacologically versus untreated ones and healthy controls. The group with untreated hypertension obtained significantly worse scores in phonemic VF, when compared to the group with treated hypertension and the normotensive ones. However, there was no significant difference between groups in the Backward Digit Span task. Similarly, in Bucur and Madden ${ }^{27}$, there was a significant difference between the SAH and normotensive groups in phonemic FV performance, suggesting that the presence of $\mathrm{SAH}$ could influence EF updating.

However, other evidence suggests that the updating is not impaired among people with $\mathrm{SAH}$, such as, for example, in the studies of Waldstein et al. ${ }^{29}$ and Alipour and Goldust ${ }^{30}$. Waldstein et al. ${ }^{29}$, for instance, found no difference between normotensive and hypertensive adults in measures of updating (Phonemic VF and Backward Digit Span). Alipour and Goldust $^{30}$ found a statistical difference between the normotensive and hypertensive groups in the Backward Digit Span 
task, with better performance among the participants with $\mathrm{SAH}$ and no difference between the groups in phonemic VF.

\section{Shifting}

In the present study, participants with more severe SAH had significantly lower performance in the TMT-B. To exclude the possibility of visual scanning ability interfering with this finding, we calculated the TMT-B minus TMT-A scores. This variable did not differentiate the clinical groups, lending some support to the idea that $\mathrm{SAH}$-associated changes in visual attention could interfere in shifting. Previous studies that analyzed the impact of SAH in the TMT-B revealed results compatible with those of the present investigation, such as Li et al. ${ }^{26}$, Bucur and Madden ${ }^{27}$ and Vicario et al. ${ }^{31}$. Vicario et al. ${ }^{31}$ reported that significant deficits in the TMT-B were present in $46 \%$ of hypertensive older adults versus $13 \%$ among normotensive ones.
In summary, the findings of the present investigation suggest that severe SAH is associated to worse performance in measures of updating and shifting. The clinical groups did not differ as to IC, but this finding may be related to the use of a less complex measure of the aforementioned ability. Among study limitations, we cite that participants did not complete neuroimaging exams, and, therefore, it was not possible to completely rule out the presence of cerebrovascular disease among participants. Considering that EF performance is greatly important for occupational roles and activities of daily living (ADL), future studies should investigate whether changes in updating and shifting have negative consequences for the daily routine of patients. Seen that indirect measures of ADL suffer from informant bias, we suggest the use of direct measures of ADL, such as the Direct Assessment of Functional Status ${ }^{32}$.

\section{References}

1. Oparil S, Acelajado MC, Bakris GL, Berlowitz DR, Cífková R, Dominiczak AF, et al. Hypertension. Nat Rev Dis Primers. 2018 Mar;4:18014. https://doi.org/10.1038/nrdp.2018.14

2. Gorelick PB, Furie KL, ladecola C, Smith EE, Waddy SP, Lloyd-Jones $\mathrm{DM}$, et al. Defining optimal brain health in adults: a presidential advisory from the American Heart Association/American Stroke Association. Stroke. 2017 Oct;48(10):e284-e303. https://doi. org/10.1161/STR.0000000000000148

3. Moser M, Roccella EJ. The treatment of hypertension: a remarkable success story. J Clin Hypertens (Greenwich). 2013 Feb;15(2):88-91. https://doi.org/10.1111/jch.12033

4. Faraco G, ladecola C. Hypertension: a harbinger of stroke and dementia. Hypertension. 2013 Nov;62(5):810-7. https://doi. org/10.1161/HYPERTENSIONAHA.113.01063

5. van Dijk EJ, Breteler MM, Schmidt R, Berger K, Nilsson LG, Oudkerk $\mathrm{M}$, et al. The association between blood pressure, hypertension, and cerebral white matter lesions: cardiovascular determinants of dementia study. Hypertension. 2004 Nov;44(5):625-30. https://doi. org/10.1161/01.HYP.0000145857.98904.20

6. Pantoni L. Cerebral small vessel disease: from pathogenesis and clinical characteristics to therapeutic challenges. Lancet Neurol. 2010 Jul;9(7):689-701. https://doi.org/10.1016/S14744422(10)70104-6

7. Schmidt EL, Burge W, Visscher KM, Ross LA. Cortical thickness in frontoparietal and cingulo-opercular networks predicts executive function performance in older adults. Neuropsychology. 2016 Mar;30(3):322-31. https://doi.org/10.1037/neu0000242

8. Arnsten AF, Wang MJ, Paspalas CD. Neuromodulation of thought: flexibilities and vulnerabilities in pre-frontal cortical network synapses. Neuron. 2012 Oct 4;76(1):223-39. https://doi. org/10.1016/j.neuron.2012.08.038

9. Lezak MD, Howieson DB, Loring DW. Neuropsychological assessment. $4^{\text {th }}$ ed. New York: Oxford University Press, 2004

10. Williams PG, Tinajero R, Suchy Y. Executive functioning and health. In: Oxford Handbooks Online. New York: Oxford University Press, 2017. 10.1093/oxfordhb/9780199935291.013.75

11. Miyake A, Friedman NP, Emerson MJ, Witzki AH, Howerter A, Wager TD. The unity and diversity of executive functions and their contributions to complex "frontal lobe tasks: A latent variable analysis. Cogn Psychol. 2000 Aug;41(1):49-100. https://doi. org/10.1006/cogp.1999.0734
12. Diamond A. Executive functions. Annu Rev Psychol. 2013;64:135-68. https://doi.org/10.1146/annurev-psych-113011-143750

13. Diamond A. The early development of executive functions. In: Bialystock E, Craik FIM, editors. Lifespan cognition: Mechanisms of change. Oxford, England: Oxford University Press, 2006. p.70-95.

14. Friedman NP, Miyake A. Unity and diversity of executive functions: Individual differences as a window on cognitive structure. Cortex. 2017 Jan;86:186-204. https://doi.org/10.1016/j.cortex.2016.04.023

15. Antelmi I, Chuang EY, Grupi CJ, Latorre MR, Mansur AJ. Heart rate recovery after treadmill electrocardiographic exercise stress test and 24 -hour heart rate variability in healthy individuals. Arq Bras Cardiol. 2008 Jun;90(6):380-5. https://doi.org/10.1590/s0066$782 \times 2008000600005$

16. Kochhann R, Varela JS, Lisboa CSM, Chaves MLF. The Mini Mental State Examination: Review of cutoff points adjusted for schooling in a large Southern Brazilian sample. Dement Neuropsychol. 2010 Jan-Mar;4(1):35-41. https://doi.org/10.1590/S198057642010 DN40100006

17. Webb AJ, Pendlebury ST, Li L, Simoni M, Lovett N, Mehta Z, et al. Validation of the Montreal cognitive assessment versus mini-mental state examination against hypertension and hypertensive arteriopathy after transient ischemic attack or minor stroke. Stroke. 2014 Nov;45(11):3337-42. https://doi.org/10.1161/STROKEAHA.114.006309

18. Hachinski V, ladecola C, Petersen RC, Breteler MM, Nyenhuis DL, Black SE, et al. National Institute of Neurological Disorders and Stroke-Canadian Stroke Network vascular cognitive impairment harmonization standards. Stroke. 2006 Sep;37(9):2220-41. https:// doi.org/10.1161/01.STR.0000237236.88823.47

19. Frota NAF, Nitrini R, Damasceno BP, Forlenza OV, Dias-Tosta E, da Silva AB, et al. Criteria for the diagnosis of Alzheimer's disease: recommendations of the Scientific Department of Cognitive Neurology and Aging of the Brazilian Academy of Neurology. Dement Neuropsychol. 2011 Jul-Sep;5(3):146-52. https://doi.org/10.1590/ S1980-57642011DN05030002

20. Gonçalves DM, Stein AT, Kapczinski F. Avaliação de desempenho do Self-Reporting Questionnaire como instrumento de rastreamento psiquiátrico: um estudo comparativo com o Structured Clinical Interview for DSM-IV-TR. Cad Saúde Pública. 2008;24(2);380-90. https://doi.org/10.1590/S0102-311X2008000200017

21. Cohen J. Statistical power analysis for the behavioural sciences. $2^{\text {nd }}$ ed. Hillsdale, NJ: Lawrence Erlbaum Associates, 1988. 
22. Tatemichi TK, Desmond DW, Stern Y, Paik M, Sano M, Bagiella E. Cognitive impairment after stroke: frequency, patterns and relationship to functional abilities. J Neurol Neurosurg Psychiatry. 1994 Feb;57(2):202-7. https://doi.org/10.1136/jnnp.57.2.202

23. Hannesdottir K, Nitkunan A, Charlton RA, Barrick TR, MacGregor GA, Markus HS. Cognitive Impairment and white matter damage in hypertension: a pilot study. Acta Neurol Scand. 2009 Apr;119(4):2618. https://doi.org/10.1111/j.1600-0404.2008.01098.x

24. Fitri FI, Rambe AS. Correlation between hypertension and cognitive function in elderly. IOP Conf Ser: Earth Environ Sci. 2018;125:012177. https://doi.org/10.1088/1755-1315/125/1/012177

25. Moraes NC, Aprahamian I, Yassuda MS. Executive function in systemic arterial hypertension: A systematic review. Dement Neuropsychol. 2019 Sep;13(3):284-92. https://doi. org/10.1590/1980-57642018dn13-030004

26. Li X, Liang Y, Chen Y, Zhang J, Wei D, Chen K, et al. Disrupted frontoparietal network mediates white matter structure dysfunction associated with cognitive decline in hypertension patients.J Neurosci. 2015 Jul;35(27):10015-24. https://doi.org/10.1523/JNEUROSCI.5113-14.2015

27. Bucur B, Madden DJ. Effects of adult age and blood pressure on executive function and speed of processing. Exp Aging Res. 2010 Apr;36(2):153-68. https://doi.org/10.1080/03610731003613482a
28. Memória CM, Muela HCS, Moraes NC, Costa-Hong VA, Machado MF, Nitrini R, et al. Applicability of the Test of Variables of Attention - T.O.V.A in Brazilian adults. Dement Neuropsychol. 2018 Dec;12(4):394-401. https://doi.org/10.1590/198057642018dn12-040009

29. Waldstein SR, Jennings JR, Ryan C, Muldoon MF, Shapiro AP, Polefrone JM, et al. Hypertension and neuropsychological performance in men: Intercative effects of age. Health Psychol. 1996 Mar;15(2):102-9. https://doi.org/10.1037//02786133.15 .2 .102

30. Alipour H, Goldust M. The association between blood pressure components and cognitive functions and cognitive reserve. Clin Exp Hypertens. 2016;38(1):95-9. https://doi.org/10.3109/10641963.2015. 1047946

31. Vicario A, Martinez CD, Baretto D, Diaz Casale A, Nicolosi L. Hypertension and cognitive decline: Impact on executive function. J Clin Hypertens. 2005;7(10):598-604. https://doi.org/10.1111/j.15246175.2005.04498.x

32. Pereira FS, Yassuda MS, Oliveira AM, Forlenza OV. Cross-cultural adaptation, reliability and validity of the DAFS-R in a sample of Brazilian older adults. Arch Clin Neuropsychol. 2010 Jun;25(4):33543. https://doi.org/10.1093/arclin/acq029 